\title{
Experimental campylobacter infection and diarrhoea in immunodeficient mice
}

\author{
A. E. HODGSON, B. W. McBRIDE, M. J. HUdSON, G. HALL and S. A. LEACH \\ Centre for Applied Microbiology and Research, Salisbury, Wiltshire, SP4 OJG
}

\begin{abstract}
The responses of previously untested immunodeficient mouse strains to campylobacter infection are described. Three strains of adult immunodeficient mice (SCID-Beige, C.B17-SCID-Beige and RAG-2) were inoculated intragastrically with Campylobacter jejuni NCTC 11168. All mice became heavily colonised, but none developed clinical signs of disease. Immunocompetent BALB/c mice inoculated similarly had much lower colonisation levels. The co-administration of iron dextran had no effect on colonisation levels nor the development of clinical signs of disease. In contrast, C.B-17-SCID-Beige mice, when inoculated with one of a series of 10 clinical isolates of $C$. jejuni, were more heavily colonised for extended periods (up to 5 months) and approximately $10-20 \%$ of the mice became ill with diarrhoea. $C$. jejuni was detected in mouse faeces throughout at levels of $10^{7}-10^{9} \mathrm{cfu} / \mathrm{g}$. All mice killed whilst ill with diarrhoea displayed histopathological lesions typical of human campylobacteriosis. Severe pathology was limited to the large intestine and was suggestive of an acute, bacteria-induced inflammation. Although blood was detected in the diarrhoeal stools, no evidence of mucosal epithelial cell invasion was found by immunohistology. No pathology was detected in tissue sections from any of the animals that had not developed signs of disease following $C$. jejuni inoculation. These immunodeficient mouse strains are readily, and heavily, colonised as adults by $C$. jejuni. The diarrhoea, although sporadic, was reproducibly produced, and could provide the basis for pathogenicity studies.
\end{abstract}

\section{Introduction}

Campylobacter jejuni is the most common cause of bacterial gastrointestinal disease in many western industrialised countries [1,2]. Symptoms are often debilitating, and typically include pyrexia, severe abdominal pain and diarrhoea [3]. Campylobacter enteritis is thought to affect $c .1 \%$ of the population per year in the UK and USA [3,4]. Although usually self-limiting, the high incidence of the disease means that $C$. jejuni constitutes a major health issue.

Studies on the organism's pathogenicity are hampered by the lack of a suitable animal model. Existing models are either cumbersome and difficult to work with (calves, ferrets) [5-7], expensive (primates) [8], inconsistent between studies (cats, dogs) [9] or fail to reproduce the symptoms of human disease (chicks, mice, rats) $[10,11]$. However, a small rodent model such as the mouse would have clear advantages in

Received 31 July 1997; revised version accepted 14 Jan. 1998.

Corresponding author: Dr A. E. Hodgson. terms of, for example, the ability to use large numbers of animals for the rigorous testing of results, their defined genetic background and the widespread availability of immunological reagents for detailed investigations. Campylobacter spp. are not normally found in laboratory mice but have been described in wild rodents [12]. Indeed, mice have been postulated as reservoir hosts for transfer of the organism to poultry [10]. Laboratory mice can become colonised, usually at low levels, with Campylobacter spp. following oral inoculation, but colonisation rates can be improved by reducing the competing gut flora by the use of antibiotics [13] or by using germ-free animals [14]. These are essentially colonisation models, as they do not generally result in diarrhoea or other signs of disease. Baqar et al. [15] have described recently a virulence model for Campylobacter spp. in which mice were inoculated intranasally with the organism. The authors did not note any diarrhoea following inoculation, rather the animals became systemically infected and died. This model may have some potential applications, but does not represent the natural route, nor consequence, of infection in man. The pre-treatment of mice with iron 
compounds, such as iron dextran, has been reported to potentiate the virulence of $C$. jejuni in mice, resulting in the development of clinical signs of disease [1618]. Coker and Obi [16] found that diarrhoea or death occurred in all mice given iron dextran along with the oral inoculum. Without iron, mice given high doses of C. jejuni $\left(10^{9-10} \mathrm{cfu}\right)$ did not develop diarrhoea. Therefore, the effect of iron on pathogenicity of $C$. jejuni was investigated as part of the present study.

Several pathogenicity studies have recognised the increased susceptibility to infection of immunocompromised mice (reviewed in [19]). Severe combined immunodeficient (SCID) mice, particularly, have been used in such studies [20-22]. Evidence suggests that these immunodeficient mice show increased susceptibility to gastrointestinal infections to which immunocompetent mice would be refractory [23]. Their specific susceptibility to campylobacter infection is described in this study. Murine SCID mutants are homozygous for a recessive mutation that impairs early lymphocyte development, and results in an absence of mature B and T lymphocytes [24]. A related strain, SCID-Beige, was used in the present study. In addition to $\mathrm{B}-$ and T-cell deficiencies, SCID-Beige mice have defective natural killer (NK) cell populations [25]. Occasionally, primitive SCID lymphocytes may succeed in differentiating into functional $\mathrm{T}$ and $\mathrm{B}$ cells. Mice possessing such lymphocytes are referred to as 'leaky' [26]. SCID-Beige mice that had been backcrossed to the C.B-17 scid/scid parent strain, but still retained the Beige marker, were also included in the present study. SCID mice are particularly attractive as infection models as they accept xenografts; the transfer of human immune cell populations to SCID mice has been used to examine human responses to infection, without the need for human volunteer studies [21]. An additional strain of immunodeficient mouse was also included for comparison. These RAG-2 mice carry a mutation in which a portion of the recombinase activating gene, RAG-2, coding region is deleted [20]. This results in a total loss of functional $B$ and $\mathrm{T}$ cells and the production of no leaky mice [19].

The purpose of the present study was to examine the responses of immunodeficient SCID and RAG-2 mice to infection with $C$. jejuni, with reference to intestinal colonisation levels (as measured by faecal excretion of the organism), illness and histopathology. Their potential for providing models of campylobacter infection and disease was assessed. The effects of animal passage and the co-administration of iron on virulence of $C$. jejuni were also determined.

\section{Materials and methods}

\section{Micro-organisms}

C. jejuni strain NCTC 11168 (NCTC, Central Public Health Laboratory, 61 Colindale Avenue, London) and a series of 10 , low-passaged isolates of $C$. jejuni obtained from human diarrhoeal infections (supplied by Bath, Southampton and Exeter Public Health Laboratories) were used. All organisms were purified, where necessary, by passage on Columbia blood agar (CBA) containing defibrinated horse blood $10 \%$ and stored at $-70^{\circ} \mathrm{C}$ on cryobeads (Microbank, Prolab, Neston).

\section{Mice}

A breeding colony of intercross progeny derived from C.B-17 scid/scid (backcross 6) mice (termed C.B-17SCID-Beige) has been established at CAMR from mice originally supplied by $\mathrm{Dr}$ A. Croy (University of Guelph, Canada). The specific pathogen-free colony of CB17-SCID-Beige mice is regularly screened for $>70$ pathogenic micro-organisms by an independent organisation. CB17-SCID-Beige mice are also screened to ensure low mouse serum immunoglobulin production (i.e., non-leakiness) with an ELISA assay [22]. RAG-2 mice were raised similarly in a colony maintained at CAMR. The scid/scid.bg/bg mice (termed SCIDBeige) were obtained from the Institute of Animal Health, Compton. BALB/c mice were used as immunocompetent controls and were obtained from Harlan Olac (Bicester). All mice were 5-7 weeks old at the time of inoculation and were housed as groups of five in micro-isolator cages. Any manipulations outside the cages were performed in a vertical laminar flow cabinet to prevent microbiological contamination. All food, water, cages and bedding were sterilised by autoclaving or irradiation before use. Food and water were supplied ad libitum.

Before entry into the study, all mice were screened twice for carriage of Campylobacter spp. Fresh faecal pellets were collected from individual mice and homogenised in $5 \mathrm{ml}$ of quarter-strength Ringers solution containing proteose peptone $1 \%$ (RP solution). Samples $(100 \mu 1)$ were plated on to duplicate campylobacter blood-free selective plates of Modified CefoperazoneCharcoal-Desoxycholate-Amphotericin (CCDA)-Preston agar (Oxoid). Plates were incubated micro-aerobically $\left(37^{\circ} \mathrm{C} ; \mathrm{CO}_{2} 5 \%, \mathrm{O}_{2} 5 \%\right)$ in a $\mathrm{CO}_{2}$ incubator with oxygen control (ASSAB T304 GF, Don Whitley, Shipley) for $48 \mathrm{~h}$. Any growth was examined by Gram's stain. None of the mice examined was found to be a carrier of Campylobacter spp.

\section{Inoculation of mice}

Campylobacter micro-organisms were recovered from frozen storage on cryobeads by plating on to CBA bilayer plates and incubating as above. Single colonies were transferred to fresh CBA plates and incubated as above for $24 \mathrm{~h}$. The $C$. jejuni isolates were harvested from these plates into sterile phosphate-buffered saline (PBS), washed twice in PBS and resuspended to the required cell density (as determined by direct count). Inocula were checked by phase-contrast microscopy for 
characteristic morphology and motility before administration to the mice. All inocula comprised $10^{9} \mathrm{cfu}$ of highly motile spiral rods. Heat-killed cells for negative controls were prepared by autoclaving such suspensions $\left(121^{\circ} \mathrm{C}, 15 \mathrm{~min}\right)$.

Each mouse was given sodium bicarbonate solution $(100 \mu 1,5 \% \mathrm{w} / \mathrm{v})$, followed immediately by the inoculum. All solutions were administered directly into the stomach via a ball-tipped gastro-oesophageal needle. Iron dextran (Sigma) $1 \mathrm{mg}$ was included with the inoculum for certain groups, as described in the text.

\section{Evaluation of the clinical status of animals}

All animals were examined daily for signs of distress such as fur ruffling or hunching. Selected faecal samples were examined for occult blood according to the manufacturer's instructions (Haemoccult, SmithKline Beecham, USA.). Faecal samples were collected regularly after inoculation. Fresh pellets were taken from each mouse, examined for stool consistency and weighed. Pellets were homogenised in RP solution $(5 \mathrm{ml})$ and appropriate serial dilutions were plated on to duplicate modified CCDA-Preston agar plates. Plates were incubated micro-aerobically for $48 \mathrm{~h}$, prior to viable count determinations.

\section{Histology}

Specimens for histological examination were prepared throughout the study. Samples of liver, stomach and small and large intestines were removed immediately after death, fixed in neutral-buffered formaldehyde $10 \%$, embedded in paraffin wax, sectioned at $5 \mu \mathrm{m}$ and stained with haematoxylin and eosin.

C. jejuni was visualised in tissue sections by indirect immunohistological staining with a primary monoclonal antibody (MAb) raised in this laboratory against outer-membrane preparations [27] of ironlimited $C$. jejuni NCTC 11828. Tissue sections were dewaxed in xylene and rehydrated via a descending series of ethanol concentrations. After rehydration, sections were pre-incubated with hydrogen peroxide solution $(3 \% \mathrm{v} / \mathrm{v})$ for $5 \mathrm{~min}$ at room temperature, to inhibit endogenous peroxidase activity, washed in PBS and incubated with a 1 in 10 dilution of normal rabbit serum in PBS for $20 \mathrm{~min}$ at room temperature. Sections were drained and incubated with undiluted primary antibody for $45 \mathrm{~min}$ at $37^{\circ} \mathrm{C}$, washed as above, incubated with a 1 in 300 dilution of rabbit anti-mouse IgG-Biotin (Dako, High Wycombe) for $45 \mathrm{~min}$ at room temperature, washed as above, and then incubated with a 1 in 500 dilution of streptavidin-peroxidase (Jackson Immunoresearch, West Grove, USA) for $45 \mathrm{~min}$ at room temperature. Finally, sections were washed as above, incubated with amino ethyl carbazole (Zymed, San Francisco, CA, USA) for
10-15 min, counterstained with haematoxylin, dehydrated and mounted with aqueous mounting solution (Zymed, San Francisco, CA, USA).

\section{Data analysis}

Bacterial counts are expressed as $\log _{10} \mathrm{cfu} / \mathrm{g}$ of faeces (wet weight). Data were analysed by analysis of variance (Simstat, Kovach, Anglesey and GLIM, OUP Oxford). Where viable counts were below the detection limit of the method, a value of one-half the lower limit of detection for that sample was included in the calculations.

\section{Results}

Intragastric challenge of mouse strains with $C$. jejuni NCTC 11168 and the effect of iron

Experiments were designed to assess the relative colonisation and disease rates in three adult immunodeficient mouse strains and to compare these data with those obtained in immunocompetent $(\mathrm{BALB} / \mathrm{c})$ mice. Single groups of BALB/c, C.B-17-SCID-Beige, SCIDBeige and RAG-2 mice were given $10^{9} \mathrm{cfu}$ of $C$. jejuni NCTC 11168 by intragastric inoculation. Single control groups for each mouse strain were given $10^{9} \mathrm{cfu}$ of heat-killed C. jejuni NCTC 11168. Iron dextran was given to corresponding groups of $\mathrm{BALB} / \mathrm{c}, \mathrm{C} . \mathrm{B}-17$ SCID-Beige and SCID-Beige mice to investigate its effect on the virulence of $C$. jejuni in adult mice. All mice were monitored for up to 11 weeks after inoculation. Faecal counts typically increased over the first 5-10 days after inoculation and then stabilised. Data from the stable period for each mouse strain were compared and are summarised in Table 1. All animals from the three strains of immunodeficient mice became colonised with $C$. jejuni at similarly high levels, as evidenced by faecal counts of $10^{5}-10^{7} \mathrm{cfu} / \mathrm{g}$. Colonisation levels for BALB/c mice were significantly lower than those for immunodeficient mice $(\mathrm{p}<0.05)$. Similar results were obtained with a fresh clinical isolate of $C$. jejuni (228584); faecal counts over the experimental period of 52 days were much higher in

Table 1. Faecal counts of $C$. jejuni in mice $(\mathrm{n}=5)$, from a range of strains, infected with $C$. jejuni NCTC 11168 , given with and without iron dextran

\begin{tabular}{lcc}
\hline Mouse strain & $\begin{array}{c}\text { Mean faecal counts, } \\
(1 \mathrm{mg})\end{array}$ & $\begin{array}{c}\text { dextran } \\
\log _{10} \mathrm{cfu} / \mathrm{g}^{*}\end{array}$ \\
\hline BALB/c & + & $3.78(3.40-4.16)$ \\
C.B-17-SCID Beige & - & $4.4(4.14-4.66)$ \\
SCID-Beige & + & $6.01(5.27-6.76)$ \\
RAG-2 & - & $6.37(5.76-6.99)$ \\
& + & $6.91(6.54-7.27)$ \\
& - & $6.79(6.15-7.42)$ \\
\end{tabular}

* Data are the stable counts following initial colonisation period (i.e., after 5-10 days). 
the immunodeficient C.B-17-SCID Beige group than in BALB/c mice (Fig. 1).

The intragastric administration of iron dextran $(1 \mathrm{mg})$ had no significant effect on faecal excretion levels in any mouse strain that was co-inoculated with $C$. jejuni NCTC 11168 ( $p>0.05$; Table 1).

No signs of illness were observed in any animal during the experiments outlined above, nor were any histopathological abnormalities seen in tissue sections.

\section{Intragastric challenge of C.B-17-SCID-Beige mice with fresh human $C$. jejuni isolates}

The response of immunodeficient mice (C.B-17-SCIDBeige) to infection with ten fresh clinical isolates of $C$. jejuni was also examined. Single groups of C.B-17SCID-Beige mice were given $10^{9} \mathrm{cfu}$ of one of 10 clinical isolates of $C$ jejuni. Another group was given $10^{9} \mathrm{cfu}$ of $C$. jejuni NCTC 11168 that had been passaged through C.B-17-SCID-Beige mice (termed $11168 / \mathrm{MP} 1)$. Control mice received $10^{9} \mathrm{cfu}$ of heatkilled cells of isolate 3286. Mice were monitored for up to 5 months after inoculation.

Mice in all treatment groups became heavily colonised with $C$. jejuni after inoculation. Faecal excretion data once colonisation levels had stabilised are summarised for each group in Table 2. C. jejuni 11168/MP1 achieved a comparatively low colonisation level, of around $10^{7.4} \mathrm{cfu} / \mathrm{g}$ of faeces, although this was higher than for the parent reference strain, NCTC 11168 $\left(10^{6.37} \mathrm{cfu} / \mathrm{g}\right.$ of faeces; Table 1$)$. Counts in all other groups ranged from $10^{7}$ to $10^{9} \mathrm{cfu} / \mathrm{g}$. Representative data, for isolate $C$. jejuni 228584 , are presented in Fig. 2 to illustrate the progression of colonisation over the experimental period.

Diarrhoea was observed in several mice from a number of groups during the experimental period. Symptoms were observed in single mice from the groups of five inoculated with C. jejuni 247 (at 28 days after inoculation), 3286 (at 50 days after

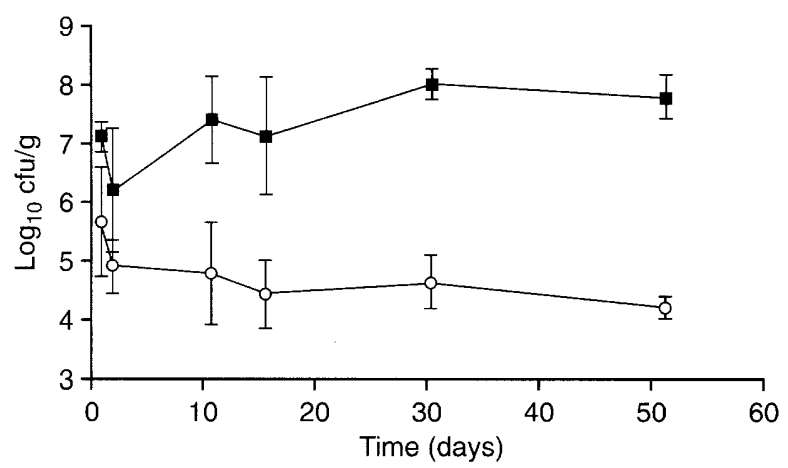

Fig. 1. Faecal excretion of $C$. jejuni isolate 228584 in immunocompetent (BALB/c; O) and immunocompromised (C.B-17-SCID-Beige; $\mathbf{0})$ mice (cfu/g faeces, wet weight). Group means and SD are shown.
Table 2. Faecal counts of a range of $C$. jejuni isolates in C.B-17-SCID Beige mice $(\mathrm{n}=5)$

\begin{tabular}{lc}
\hline Isolate code & $\begin{array}{c}\text { Mean faecal counts, } \log _{10} \mathrm{cfu} / \mathrm{g}^{*}(95 \% \\
\text { confidence limits })\end{array}$ \\
\hline $11168 \mathrm{MP1}$ & $7.40(7.21-7.58)$ \\
235 & $8.05(7.8-8.25)$ \\
247 & $9.03(8.80-9.25)$ \\
3286 & $6.80(6.06-7.53)$ \\
228961 & $8.05(7.65-8.46)$ \\
228749 & $8.53(8.30-8.76)$ \\
228487 & $8.21(7.91-8.50)$ \\
3250 & $8.62(8.19-9.04)$ \\
228735 & $8.16(7.81-8.51)$ \\
229328 & $7.95(7.50-8.39)$ \\
228584 & $8.52(8.20-8.84)$ \\
\hline
\end{tabular}

${ }^{*}$ Data are the stable counts following initial colonisation (i.e., after $5-10$ days).

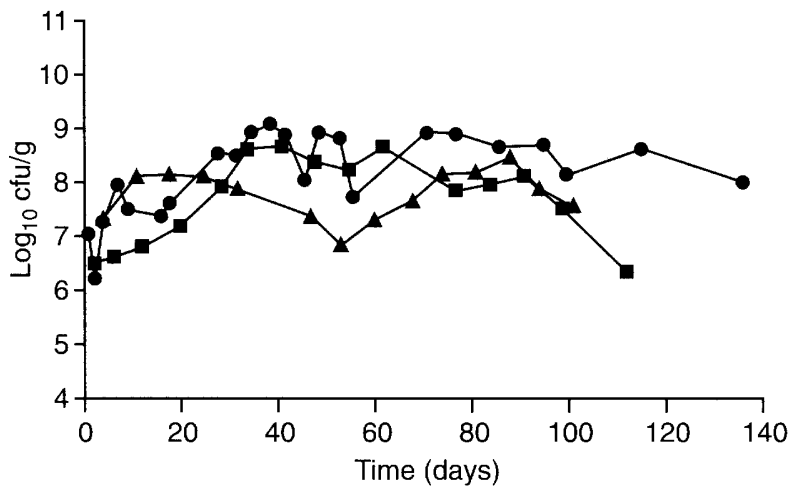

Fig. 2. Faecal excretion of clinical isolate $C$. jejuni 228584 in C.B-17-SCID-Beige mice. Data from first $(\boldsymbol{\bullet}, \mathrm{n}=5)$, second $(\boldsymbol{\Delta}, \mathrm{n}=10)$ and third $(\boldsymbol{\square}, \mathrm{n}=10)$ experiments; see text for details.

inoculation) and 229328 (at 137 days after inoculation). Two further mice, inoculated with $C$. jejuni 228584, developed diarrhoea at 29 and 66 days after inoculation, respectively. Mice with diarrhoea were hunched, had ruffled fur and drank water frequently. Diarrhoeal stools were soft, wet, mucoid and often tested positive for occult blood. The first animal to develop diarrhoea in the group inoculated with $C$. jejuni 228584 also had frank blood in the stools. In the mouse given $C$. jejuni 247 , the diarrhoea resolved within a few days. The mouse given C. jejuni 3286 developed intermittent diarrhoea throughout the experimental time course. Those animals which were killed within a few days of symptoms developing displayed histopathological lesions typical of human campylobacteriosis (discussed below). The inoculation of CB17-SCID-Beige mice with isolate $C$. jejuni 228584 was repeated on two subsequent occasions. During the 98-day study period of the first of these experiments, two of 10 mice developed diarrhoea at 41 days after inoculation. During the 102-day study period of the second experiment, two of 10 mice became ill at 62 and 102 days after inoculation. Faecal excretion data from these two experiments were similar to the initial experiment described, and are also presented in Fig. 2. 


\section{Pathology}

Abnormalities were not detected at necropsy of mice that were not displaying clinical signs of disease. In the mice with diarrhoea, pathological lesions were restricted to the large intestine; no pathology was noted consistently in the small intestines, stomach or liver. Severe reddening of the colonic and caecal mucosa was noted in all mice that had been killed whilst displaying clinical signs of enteric disease. Microscopic examination revealed that the mucosa was thickened markedly in some areas because of infiltration of the lamina propria by neutrophilic polymorphonuclear leucocytes, macrophages and small mononuclear cells (Fig. 3a and b). The mucosa was also thickened by crypt enlargement due to crypt cell hypertrophy and hyperplasia (Fig. 4a), in marked contrast to the mucosa of an uninfected mouse (Fig. 4b). Sloughed degenerate cells were seen in the intestinal lumen, and in the lumen of some crypts (Fig. 3b) and some areas of the mucosa were depleted of crypts (Fig. 5). The number of goblet cells was reduced, and foci of epithelial ulceration were
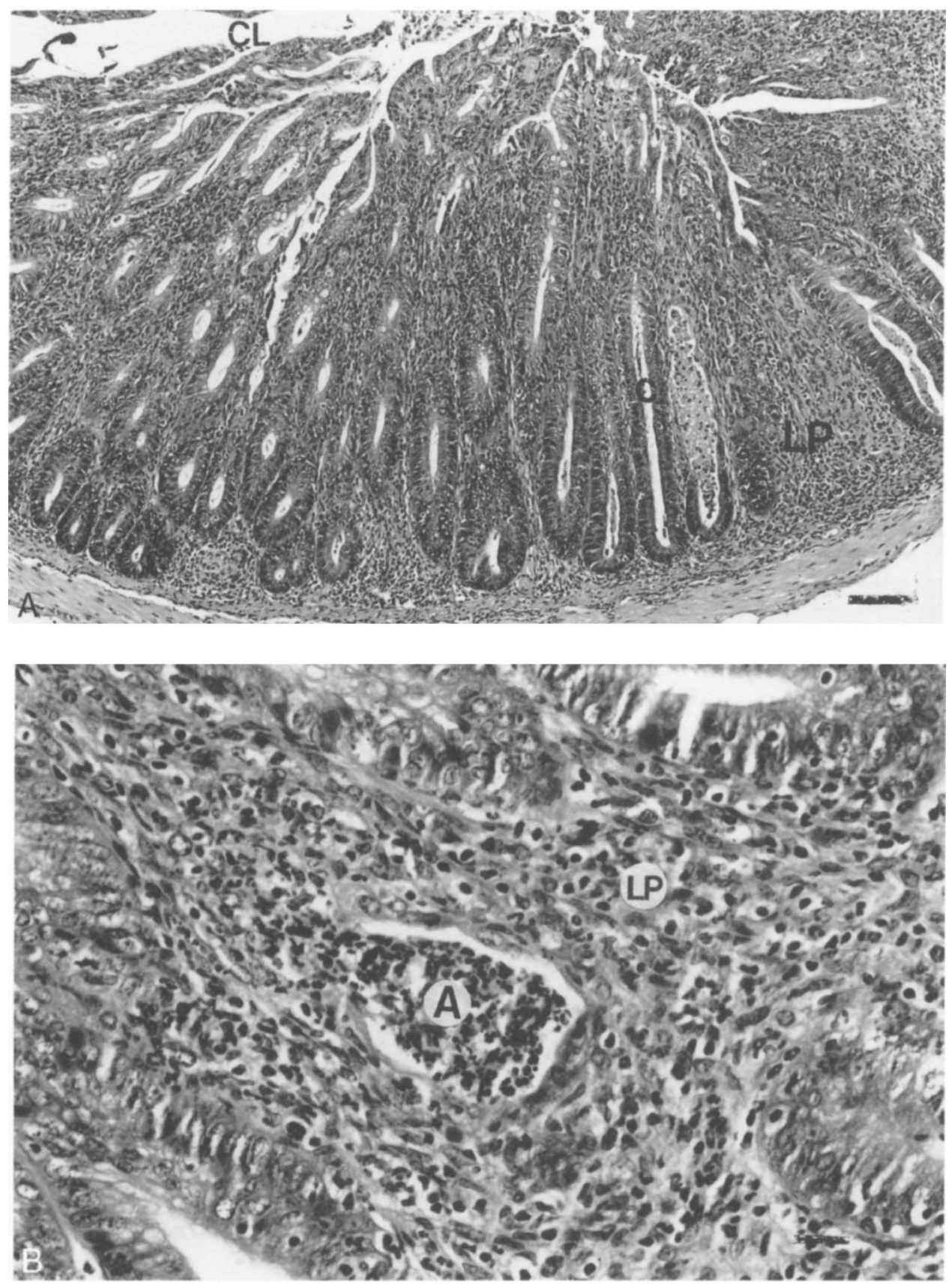

Fig. 3. Colon of C.B-17-SCID-Beige mouse that had developed diarrhoea following infection with C. jejuni 228584 . a, the mucosa is thickened, crypts (e.g., C) are elongated and the lamina propria (LP) is infiltrated by polymorphonuclear leucocytes and mononuclear inflammatory cells. Sloughed epithelial cells are present in the colonic lumen (CL). $\mathrm{H} \& \mathrm{E} \times 10 \mathrm{obj} . \quad \mathrm{Bar}=100 \mu \mathrm{m}$. b, the lamina propria (LP) is infiltrated by polymorphonuclear leucocytes and mononuclear inflammatory cells. A crypt abscess lacking epithelium is present (A) and contains degenerate crypt cells and polymorphonuclear leucocytes. H\&E $\times 40 \mathrm{obj}$. Bar $=20 \mu \mathrm{m}$. 

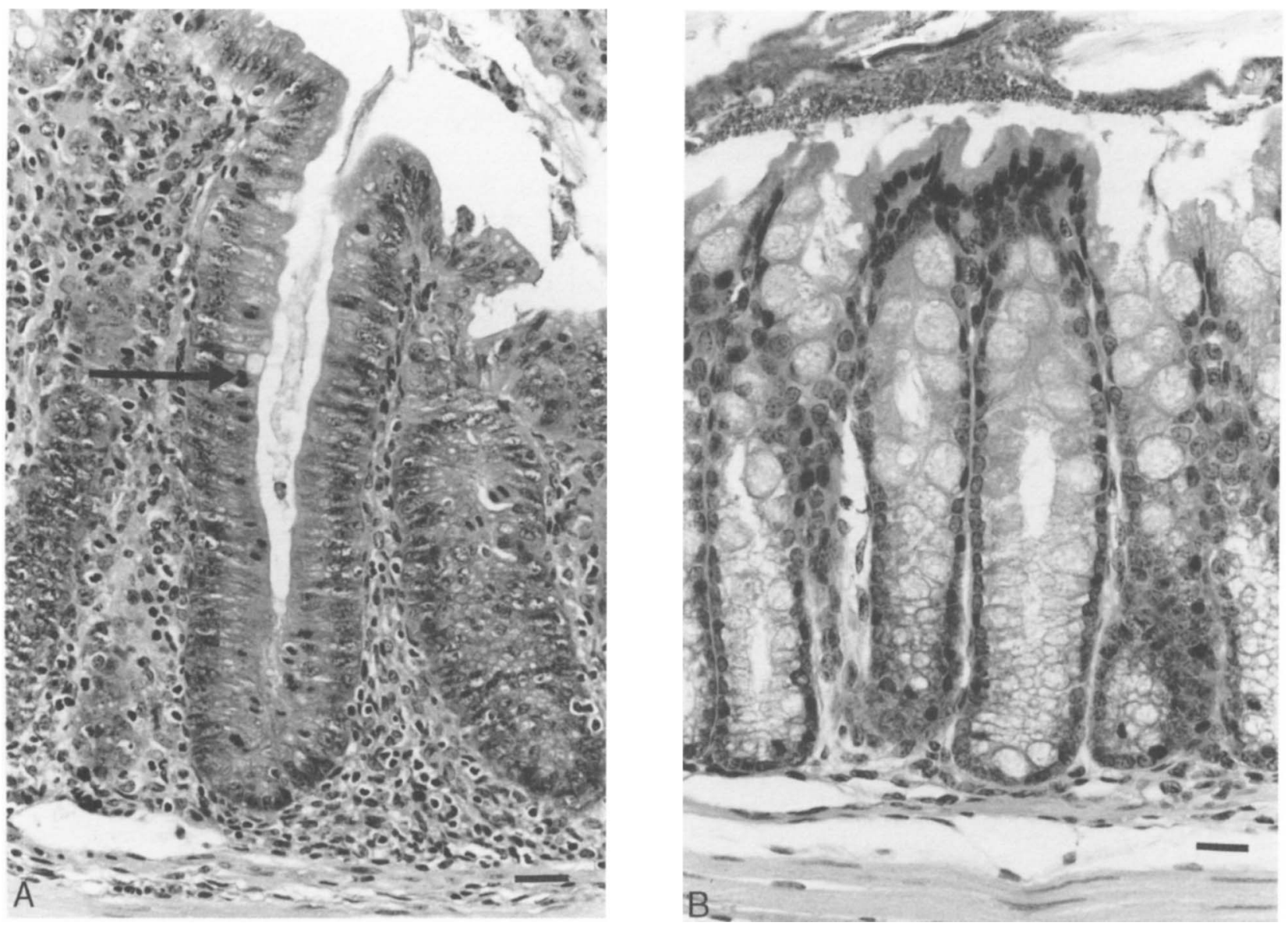

Fig. 4a. Colon of C.B-17-SCID-Beige mouse infected with C. jejuni 228584 as for Fig. 3. The crypt enterocytes are hypertrophied and crypt cell hyperplasia is indicated by many mitotic figures (arrow). Goblet cells are virtually absent. The lamina propria is infiltrated by polymorphonuclear leucocytes and macrophages. $\mathrm{H} \& \mathrm{E} \times 40 \mathrm{obj}$. Bar $=20 \mu \mathrm{m}$. b, Colon of control C.B-17-SCID mouse that had been inoculated with heat-killed C. jejuni 228584. The crypts are short and composed predominantly of goblet cells. Mitotic figures are absent and the lamina propria is devoid of inflammatory cells. H\&E $\times 40 \mathrm{obj}$. Bar $=20 \mu \mathrm{m}$.

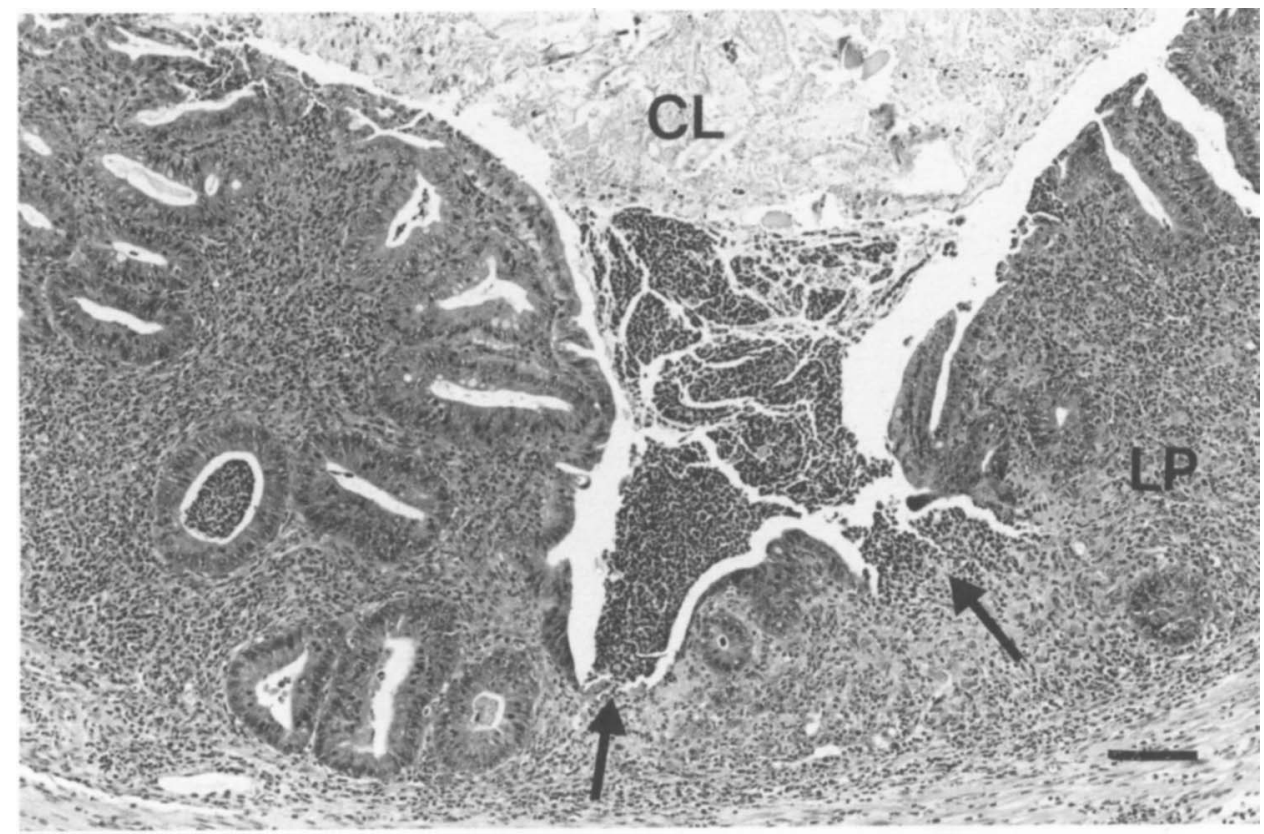

Fig. 5. Section as for Fig. 3. The lamina propria (LP) is infiltrated markedly by inflammatory cells and the number of crypts is depleted. Two foci of epithelial ulceration are present (arrows), through which neutrophilic polymorphonuclear leucocytes appear to have migrated into the colonic lumen (CL). H\&E $\times 10 \mathrm{obj}$. Bar $=100 \mu \mathrm{m}$. 
seen in association with neutrophils in the intestinal lumen (Fig. 5). Crypt abscesses were also noted (Fig. $3 b)$.

Fig. 6 demonstrates the reactivity of the MAb used as the primary antibody during immunoperoxidase staining of paraffin-embedded tissue sections from the diseased animals. This MAb recognises a $45-\mathrm{kDa}$ antigen in whole-cell protein preparations of $C$. jejuni. 228584 and showed no cross-reactions with mouse tissue antigens or commensal flora in uninfected tissue sections (Fig. 7a). Immunoperoxidase staining revealed the presence of $C$. jejuni antigen in the intestinal lumen and in crypts, but did not provide evidence of cellular invasion (Fig. 7b).

\section{Discussion}

The results of this study demonstrate that adult immunodeficient mice (SCID-Beige, C.B-17-SCIDBeige and RAG-2) can be infected by the intragastric

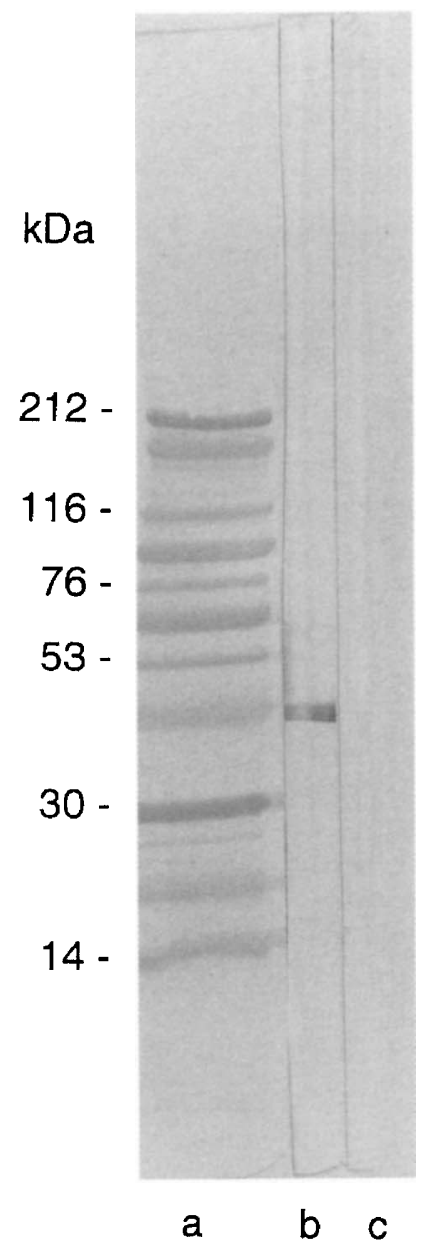

Fig. 6. Blot of C. jejuni 228584 whole-cell proteins, incubated with undiluted MAb (b) or undiluted normal mouse serum (c). Immunoblots were subsequently incubated with secondary antibody (rabbit anti-mouse IgG and IgM, 1 in 1000) and amino-ethylcarbazole as chromogen. Protein mol.wt markers were blotted and stained with amido black (a) [28]. route with $C$. jejuni without surgical or pharmacological pre-treatment of the animals. Subsequently, the organism can be isolated from faeces in high numbers over extended periods (up to 20 weeks). In general, following initial colonisation, mice showed faecal excretion levels which remained stable and consistent. Many other workers have found it necessary to treat immunocompetent mice with substances such as iron $[16,17]$ or antibiotics [13] to establish colonisation following oral inoculation, although some have described colonisation of conventional mice with $C$. jejuni without pre-treatment $[10,17]$. Berntson et al. [10] described the faecal excretion of $C$. jejuni at levels of $10^{3}-10^{5} \mathrm{cfu} / \mathrm{g}$ of faeces over a 27 -week period after challenge. The extent of colonisation depended on both the strain of mouse and of $C$. jejuni. These colonisation levels are consistent with those seen for the conventional $\mathrm{BALB} / \mathrm{c}$ mice used in the present study. However, colonisation levels were much higher than this in the present study with C.B-17-SCID-Beige mice $\left(10^{6}-10^{9} \mathrm{cfu} / \mathrm{g}\right)$.

Colonisation accompanied by diarrhoea has been recorded only rarely in conventional adult mice with a normal microflora following oral administration of C. jejuni. In all cases, some pre-treatment of the animals was necessary. Coker and Obi [16] observed disease symptoms including diarrhoea in 3-week-old mice inoculated intragastrically with $C$. jejuni when iron dextran was co-administered; animals not given iron failed to become ill. Stanfield et al. [17] also noted the necessity of iron dextran in the establishment of campylobacter disease in mice. The precise role of iron in these studies is unclear, but it could be interfering in the iron regulatory defence mechanisms of the host [29] or potentiating key virulence factors [30]. In the present study, co-administration of iron dextran did not produce signs of disease in either immunocompetent $(\mathrm{BALB} / \mathrm{c})$ or immunodeficient (SCID-Beige/C.B-17-SCID-Beige) mice inoculated with the same strain of $C$. jejuni as used by Coker and Obi [16], nor was a significant effect of iron on faecal excretion levels of the organism found $(p>0.05)$. Although the inability to reproduce the findings of Coker and Obi [16] in the present study may result from differences in the age or strain of mouse, or in experimental methodology, the coadministration of iron dextran is clearly not a reliable means of influencing the virulence of $C$. jejuni in mice.

A marked difference in faecal excretion levels of $C$. jejuni was observed between immunocompetent and immunodeficient mice. Individual BALB/c mice either eliminated the organism, or became colonised at much lower levels, usually up to three $\log$ cycles lower than the corresponding immunodeficient mice. This suggests that the lack of functional lymphocytes in immunodeficient mice predisposes them to much higher colonisation levels. This observation is con- 

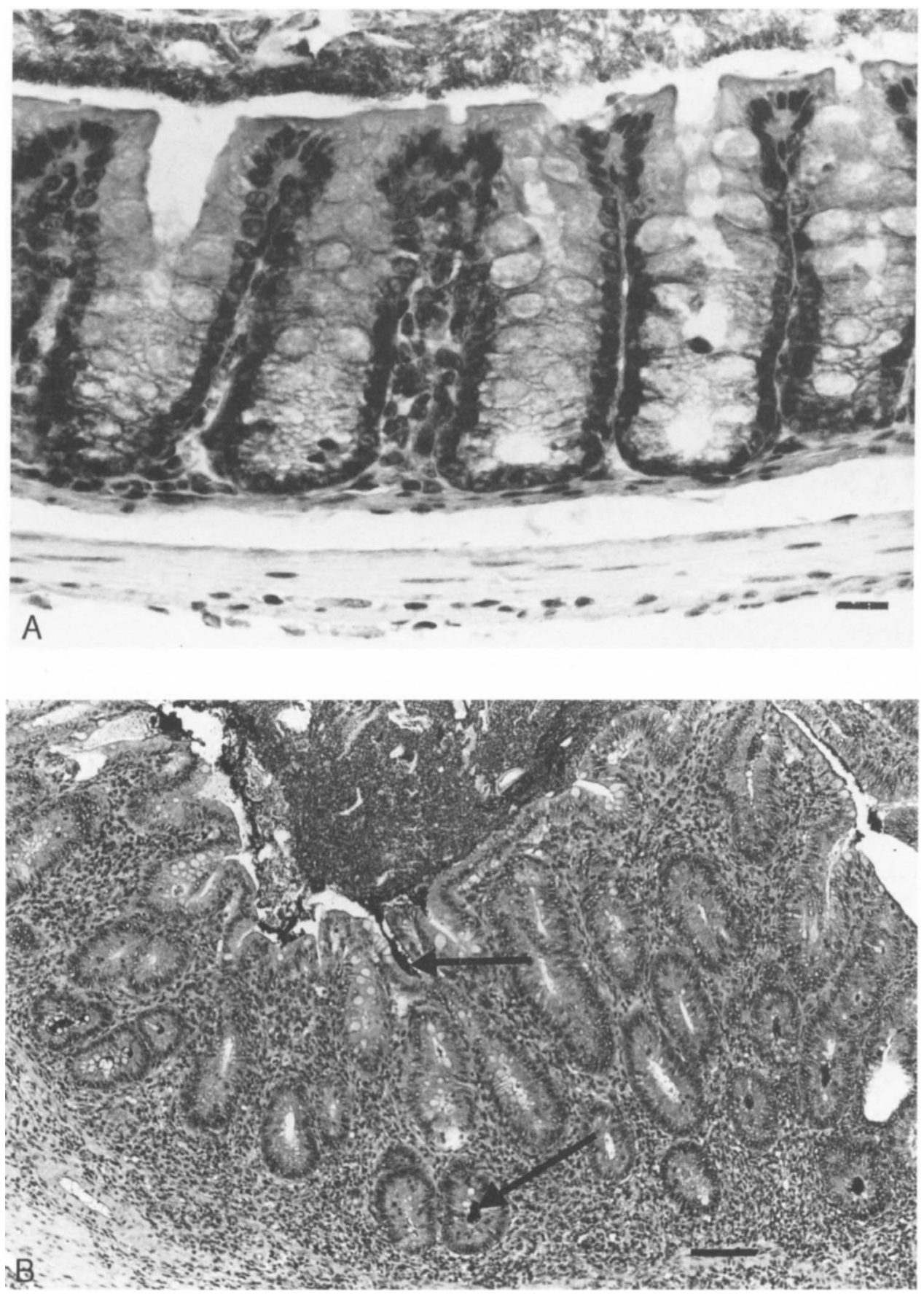

Fig. 7a. Immunostained colon section from control C.B-17-SCID-Beige mouse that had been inoculated with heatkilled $C$. jejuni. Crypts are free of immunostained $C$. jejuni. Immunoperoxidase $\times 40$ obj. $B a r=20 \mu \mathrm{m}$. b, Immunostained colon section from C.B-17-SCID-Beige mouse infected with $C$. jejuni 228584 as before. C. jejuni antigen is present in the colonic lumen and both superficially, and deep, within crypts (arrows). Immunoperoxidase $\times 10 \mathrm{obj}$. Bar $=100 \mu \mathrm{m}$.

sistent with substantial clinical and experimental evidence suggesting that humoral immune responses are important in the control of $C$. jejuni infections. Hypogammaglobulinaemic patients, for instance, have difficulty clearing campylobacter infections; an effect which is most common in patients with $\operatorname{IgA}$ deficiency [31]. There is little information on the role of cellmediated immunity in $C$. jejuni infections, although the increased frequency of this disease amongst HIVpositive individuals suggests some involvement of cell-mediated immunity in defence against $C$. jejuni infection [32]. Yrios and Balish [33] found that a competent T-cell-mediated immune response was important in the prevention of campylobacter disease symptoms in gnotobiotic mice. Baqar et al. [34] observed high levels of specific secretory IgA production and a strong $\mathrm{T}$-cell response in mice following intragastric challenge with $C$. jejuni. Protection from disease or colonisation has also been demonstrated in animals possessing a specific immune response against $C$. jejuni, having been previously exposed to the pathogen [35]. 
This study has shown that $C$. jejuni can cause diarrhoea in c. $10-20 \%$ of C.B-17-SCID-Beige immunocompromised adult mice, providing that experiments are continued for extended periods. Previous observations of $C$. jejuni-induced diarrhoea in mice have required pre-treatment of the animals with drugs or surgery [17], or the use of very young [36] or germ-free animals [33]. Field et al. [37] recorded the occurrence of diarrhoea in a number of dams of neonatal mice infected with Campylobacter spp. Although the dams were not deliberately infected, it was suggested that they had acquired the infection from their offspring; passage through the neonates may have enhanced the virulence of the organism. Although they elicited high colonisation levels, the majority of isolates tested in the present study (7 of 11) did not cause any signs of disease. Of the remaining four strains, only $10-20 \%$ of mice developed signs of $C$. jejuni enteritis. Although not ideal for pathogenicity studies, this low disease rate is not dissimilar to the situation in human campylobacter infection. A high rate of asymptomatic carriage of the organism is certainly a feature of the epidemiology of the disease in developing countries [38]. Furthermore, in one Western study, only $46 \%$ of human volunteers given large doses of C. jejuni $\left(2 \times 10^{9} \mathrm{cfu}\right)$ became ill with diarrhoea, although all were infected [39]. In human populations, low illness to infection ratios are considered to be due to the possession of protective immunity following previous natural infection. However, this interpretation could clearly not apply to the immunodeficient mouse strains used in the present study. One possible explanation for the low illness to infection ratio in the present study is an increased predisposition to illness developing in that small number of mice which may have become 'leaky' as they aged. The proportion of SCID mice that develop leakiness has indeed been reported to increase with age [40]. Similar effects in C.B-17-SCID-Beige mice are conceivable, and the possibility that certain elements of a more functional immune system are necessary for the development of campylobacter disease in these mice requires investigation. The development of leakiness as a co-factor in the occurrence of diarrhoea may also explain the prolonged incubation times seen in the present study; clinical signs of $C$. jejuni enteritis were first observed in C.B-17-SCID-Beige mice some considerable time after inoculation (28-136 days after inoculation). This contrasts with the reported incubation period for human patients of 2-5 days [1]. During this incubation period the animals were heavily colonised with $C$. jejuni, as evidenced by faecal monitoring. Other explanations for this long incubation period could include potentiation of the virulence of the organism during mouse passage, similar to that observed by Field et al. [37]. Other workers have also reported virulence enhancement of Campylobacter spp. following mouse passage [18]. Individual mice within each cage are probably constantly re-inoculating themselves via the faecal-oral route. However, an increase in the virulence of the organism after mouse passage could not be demonstrated in the present study when investigated separately, under controlled conditions. Neither strains recovered from the faeces nor diarrhoeal stools themselves showed any increased virulence in SCID mice over the time course of the experiment (data not shown).

This study provides information on lesion pathogenesis in mice. The histopathological lesions seen in the gastrointestinal tract of the C.B-17-SCID-Beige mice with diarrhoea bore remarkable similarity to those seen in biopsy samples from human subjects with campylobacter enteritis. In man, as in mice, campylobacter enteritis is primarily a disease of the colon. The human disease is associated with dense inflammatory infiltrates of neutrophils and mononuclear cells in the lamina propria, degeneration and ulceration of the mucosal epithelium and, in severe cases, the presence of crypt abcesses [41, 42]. Many of these features were seen in the sections from diarrhoeal mice. Acute inflammatory responses in the intestinal mucosa are often stimulated by invasive pathogens and may be mediated by cytokines, induced by penetration of the intestinal epithelium [43]. Invasion may be a major pathogenic mechanism for C. jejuni [35], causing tissue damage similar to that seen during infection with Shigella spp. or enteroinvasive Escherichia coli. However, in the present study, there was no direct evidence of invasion, although blood was detected in the diarrhoeic faeces. This bleeding probably originated from the eroded and ulcerated mucosa. In the present study, it seems more likely that tissue damage was caused by an extracellular toxin. Indeed, $C$. jejuni is reported to produce a number of extracellular toxins, although their roles in disease remain controversial [44]. Similar toxin-mediated damage is produced by other pathogens, e.g., in verocytotoxin-producing $E$. coli (VTEC) infection and in pigs with swine dysentery. Patients infected with VTEC strains, such as E. coli O157, develop acute colitis and bloody diarrhoea, but invasion is not thought to be important in pathogenesis. Rather, verotoxin (Shiga-like toxin) is produced which damages intestinal epithelial cells and capillaries [45]. An acute mucohaemorrhagic colitis is also seen in pigs infected with Serpulina hyodysenteriae that develop swine dysentery [46]. The bacterium colonises the intestinal crypts, as $\operatorname{did} C$. jejuni in the present study, but does not invade the mucosa - the intestinal damage is thought to be toxin-mediated.

The present study has demonstrated the increased susceptibility of certain immunodeficient mouse strains to infection with $C$. jejuni. These mouse strains, particularly the C.B-17-SCID-Beige used in the majority of these studies, can be reconstituted with elements of functional human immune systems [22]. Such human-mouse chimeras have been widely used 
as models in the study of human immune responses to infection. Similar studies with Campylobacter spp. may provide valuable information on host response to campylobacter infection.

In summary, the administration of $C$. jejuni to immunodeficient C.B-17-SCID-Beige, SCID-Beige and RAG- 2 mice resulted in a persistent colonisation of the gastrointestinal tract. When fresh clinical isolates of $C$. jejuni were used, high numbers of the organism $\left(10^{7}-10^{9} \mathrm{cfu} / \mathrm{g}\right)$ were consistently excreted in the faeces. In c. $10-20 \%$ of these mice, clinical signs typical of campylobacter enteritis developed after several weeks of colonisation. Although this time course does not mimic the typical incubation period in man, the clinical signs and histopathological lesions were representative of those seen in the human disease. Furthermore, the occurrence of campylobacter diarrhoea in C.B-17-SCID-Beige immunodeficient mice was reproducible, adding considerably to their potential for pathogenesis studies with Campylobacter spp. As there would be clear benefits in shortening the time course for disease and increasing the proportion of ill mice, this will be the focus of further study. Reconstitution experiments with human and other mammalian immune components would also allow different host responses to campylobacter infection to be compared.

This study was supported by the Department of Health. The authors also thank A. Swan and N. Soltanpoor (PHLS Statistics Unit) for statistical advice and analysis. We acknowledge the care and support of animals by staff from the Biological Investigations Group, CAMR.

\section{References}

1. Advisory Committee on the Microbiological Safety of Food. Interim Report on Campylobacter and Recommendations and Government's Response. London, HMSO. 1993.

2. Tauxe RV. Epidemiology of Campylobacter jejuni infections in the United States and other industrialised nations. In: Nachamkin I, Blaser MJ, Tompkins LS (eds) Campylobacter jejuni: current status and future trends. Washington, DC, American Society for Microbiology. 1992: 9-19.

3. Walker RI, Caldwell MB, Lee EC, Guerry P, Trust TJ, RuizPalacios GM. Pathophysiology of Campylobacter enteritis. Microbiol Rev 1986; 50: 81-94.

4. Kendall EJC, Tanner El. Campylobacter enteritis in general practice. J Hyg 1982; 88: 155-163.

5. Bell JA, Manning DD. A domestic ferret model of immunity to Campylobacter jejuni-induced enteric disease. Infect Immun 1990; 58: $1848-1852$

6. Fox JG, Ackerman JI, Taylor N, Claps M, Murphy JC. Campylobacter jejuni infection in the ferret: an animal model of human campylobacteriosis. Am J Vet Res 1987; 48: 85-90.

7. Firehammer BD, Myers LL. Campylobacter fetus subsp. jejuni: its possible significance in enteric disease of calves and lambs. Am $J$ Vet Res 1981; 42: 918-922.

8. Fitzgeorge RB, Baskerville A, Lander KP. Experimental infection of Rhesus monkeys with a human strain of Campylobacter jejuni. J Hyg 1981; 86: 343-351.

9. Prescott JF, Karmali MA. Attempts to transmit campylobacter enteritis to dogs and cats. Can Med Assoc J 1978; 119: 1001.

10. Berndson E, Danielsson-Tham ML, Engvall A. Experimental colonization of mice with Campylobacter jejuni. Vet Microbiol 1994; 41: 183-188.

11. Sanyal SC, Islam KMN, Neogy PKB, Islam M, Speelman P, Huq MI. Campylobacter jejuni diarrhea model in infant chickens. Infect Immun 1984; 43: $931-936$

12. Pacha RE, Clark GW, Williams EA, Carter AM, Scheffelmaier JJ, Debusschere P. Small rodents and other mammals associated with mountain meadows as reservoirs of Giardia spp. and Campylobacter spp. Appl Environ Microbiol 1987; 53: $1574-1579$

13. Field LH, Underwood JL, Berry LJ. The role of gut flora and animal passage in the colonisation of adult mice with Campylobacter jejuni. J Med Microbiol 1984; 17: 59-66.

14. Yrios JW, Balish E. Colonization and infection of athymic and euthymic germfree mice by Campylobacter jejuni and Campylobacter fetus subsp. fetus. Infect Immun 1986; 53: 378-383.

15. Baqar S, Bourgeois AL, Applebee LA et al. Murine intranasal challenge model for the study of Campylobacter pathogenesis and immunity. Infect Immun 1996; 64: 4933-4939.

16. Coker AO, Obi CL. Effect of iron-dextran on the lethality of Nigerian isolates of Campylobacter jejuni in mice. Cent Afr $J$ Med 1991; 37: 20-23.

17. Stanfield JT, McCardell BA, Madden JM. Campylobacter diarrhea in an adult mouse model. Microb Pathog 1987; 3: $155-165$.

18. Kazmi SU, Roberson BS, Stern NJ. Animal-passaged, virulence-enhanced Campylobacter jejuni causes enteritis in neonatal mice. Curr Microbiol 1984; 11: 159--164.

19. Kaufmann SHE, Ladel CH. Application of knockout mice to the experimental analysis of infections with bacteria and protozoa. Trends Microbiol 1994; 2: 235-242.

20. Shinkai Y, Rathbun G, Lam K-P et al. RAG-2 deficient mice lack mature lymphocytes owing to inability to initiate $V(D) J$ rearrangement. Cell 1992; 68: 855-867.

21. Torbett BE, Picchio G, Mosier DE. hu-PBL-SCID mice - a model for human immune function, AIDS, and lymphomagenesis. Immunol Rev 1991; 124: 139-164.

22. Williams A, McBride BW, Hall G, Fitzgeorge RB, Farrar GH Experimental Legionnaires' disease in SCID-Beige mice reconstituted with human leucocytes. J Med Microbiol 1995; 42: $433-441$.

23. Mead JR, Arrowood MJ, Sidwell RW, Healey MC. Chronic Cryptosporidium parvum infections in congenitally immunodeficient SCID and nude mice. J Infect Dis 1991; 163: 1297-1304.

24. Bosma MJ, Carroll AM. The SCID mouse mutant: definition, characterization and potential uses. Annu Rev Immunol 1991; 9: $323-350$.

25. MacDougall JR, Croy BA, Chapeau C, Clark DA. Demonstration of a splenic cytotoxic effector cell in mice of genotype SCID/SCID.BG/BG. Cell Immunol 1990; 130: 106-117.

26. Bosma MJ. B and T cell leakiness in the SCID mouse mutant. Immunodefic Rev 1992; 3: 261-276.

27. Filip C, Fletcher G, Wulff JL, Earhart CF. Solubilization of the cytoplasmic membrane of Escherichia coli by the ionic detergent sodium-lauryl sarcosinate. J Bacteriol 1973; 115: $717-722$.

28. Towbin H, Staehelin J, Gordon J. Electrophoretic transfer of proteins from polyacrylamide gels to nitrocellulose sheets: procedure and some applications. PNAS (US) 1979; 76: $4350-5354$.

29. Weinberg EB. Iron and infection. Microbiol Rev 1978; 42: $45-66$.

30. McCardell BA, Madden JM, Stanfield JT. Effect of iron concentration on toxin production in Campylobacter jejuni and Campylobacter coli. Can J Microbiol 1986; 32: 395-401.

31. Johnson RJ, Nolan C, Wang SP, Shelton WR, Blaser MJ. Persistent Campylobacter jejuni infection in an immunocompromised patient. Ann Int Med 1984; 100: 832-834.

32. Sovillo FJ, Lieb LE, Waterman SH. Incidence of campylobacteriosis among patients with AIDS in Los Angeles County. $J$ Acquir Immune Defic Syndr 1991; 4: 598-602.

33. Yrios JW, Balish E. Pathogenesis of Campylobacter spp. in athymic and euthymic germfree mice. Infect Immun 1986; 53: 384-392.

34. Baqar S, Applebee LA, Lubold M, Bourgeois AL. Characteristics of humoral and cellular immunity to Campylobacter jejuni in mice following infection or vaccination. In: Newell DG, Ketley J, Feldman RA (eds) Campylobacters, helicobacters and related organisms. New York, Plenum Press. 1996: 721.

35. Ruiz-Palacios GM, Lopez-Vidal Y, Lopez-Vidal AB, Torres J, Rubio S. Systemic and local immune response in experimental campylobacter infection In: Pearson AD, Skirrow MB, Rowe B Davies JR, Jones DM (eds) Campylobacter II. London, Public Health Laboratory Service. 1983: 115-116. 
36. Manninen KI, Prescott JF, Dohoo IR. Pathogenicity of Campylobacter jejuni isolates from animals and humans. Infect Immun 1982; 38: 46-52.

37. Field LH, Underwood JL, Pope LM, Berry LJ. Intestinal colonization of neonatal animals by Campylobacter fetus subsp. jejuni. Infect Immun 1981; 33: 884-892.

38. Taylor DN. Campylobacter infections in developing countries. In: Nachamkin 1, Blaser MJ, Tomkins LS (eds) Campylobacter jejuni: current status and future trends. Washington, DC, American Society for Microbiology. 1992: 20-30.

39. Black RE, Levine MM, Clements ML, Hughes TP, Blaser MJ. Experimental Campylobacter jejuni infection in humans. $J$ Infect Dis 1988; 157: 472-479.

40. Nonoyama S, Smith FO, Bernstein ID, Ochs HD. Straindependent leakiness of mice with severe combined immune deficiency. $J$ Immunol 1993; 150: 3817-3824.
41. Blaser MJ, Reller LB. Campylobacter enteritis. $N$ Engl $J$ Med 1981; 305: 1444-1452.

42. Lambert $\mathrm{ME}$, Schofield $\mathrm{PF}$, Ironside $\mathrm{AG}$, Mandal BK. Campylobacter colitis. BMJ 1979; 1: 857-859.

43. Jung HC, Eckmann L, Yang S-K et al. A distinct array of proinflammatory cytokines is expressed in human colon epithelial cells in response to bacterial invasion. $J$ Clin Invest 1995; 95: $55-65$.

44. Wassenaar TM. Toxin production by Campylobacter spp. Clin Microbiol Rev 1997; 10: 466-476.

45. Tesh VL, O'Brien AD. Adherence and colonization mechanisms of enteropathogenic and enterohemorrhagic Escherichia coli. Microb Pathog 1992; 12: 245-254.

46. Hindersson P, Thomas D, Stamm L, Penn C, Norris S, Joens LA. Interaction of spirochetes with the host. Res Microbiol 1992; 143: 629-639. 